\title{
Nighttime Cholecystectomies are Safe When Controlled for Individual Patient Risk Factors-A Nationwide Case-Control Analysis
}

\author{
Kian Merati-Kashani ${ }^{1} \cdot$ Claudio Canal $^{2} \cdot$ Dominique Lisa Birrer $^{3} \cdot$ Pierre-Alain Clavien $^{3} \cdot$ \\ Valentin Neuhaus ${ }^{2} \cdot$ Matthias Turina $^{3}$
}

\begin{abstract}
Background The aim of this study was to evaluate if the time of day a cholecystectomy was performed affects inhospital complication rates and mortality.

Methods A national quality measurement database was retrospectively studied. Study period was 2010 to 2017. The inclusion criteria were operatively treated cholecystitis or another benign disease of the gallbladder. Further, the time of day the operation was performed must have been documented. We defined nighttime as all interventions performed between 7PM until 6AM. A total of 11'459 patients were included. Development of any complication during hospitalization and in-hospital mortality was the main outcomes. The first part of the study was solely descriptive. In the second part, we applied a 1:1 case-control-matching. A matched group of 274 pairs were further investigated. Results Only $8.4 \%$ of the procedures were performed during nighttime. Complications occurred in $6.7 \%$ of all patients. We found twice as many complications in the nighttime group compared to the daytime group. Mortality was $0.56 \%$ during daytime and $0.52 \%$ during nighttime. In a matched-pair analysis, however, we found no significant differences in the overall mortality rate nor in the occurrence of complications when comparing day- vs. nighttime operations.

Conclusions We found twice as many complications in the nighttime group (12\%) compared to the daytime group (6.1\%), mainly related to patient risk factors. In contrast to common apprehension, however, nighttime cholecystectomies were not associated with higher mortality rates.
\end{abstract}

Supplementary Information The online version contains supplementary material available at https://doi.org/10.1007/s00268021-06021-7.

Matthias Turina

Matthias.Turina@usz.ch

Kian Merati-Kashani

kian.merati-kashani@spital-limmattal.ch

Claudio Canal

Claudio.canal@bluewin.ch

Dominique Lisa Birrer

Dominique.Birrer@usz.ch

Pierre-Alain Clavien

clavien@access.uzh.ch
Valentin Neuhaus

Valentin.Neuhaus@gmx.ch

1 Department of Surgery, Hospital of Maennedorf, Asylstrasse 10, CH-8708 Maennedorf, Switzerland

2 Division of Trauma Surgery, Department of Traumatology, University Hospital Zurich, University of Zurich, Raemistrasse 100, CH-8091 Zurich, Switzerland

3 Department of General and Transplant Surgery, University Hospital Zurich, University of Zurich, Raemistrasse 100, CH-8091 Zurich, Switzerland 


\section{Introduction}

The standard treatment for symptomatic cholecystolithiasis as well as for acute cholecystitis is surgical removal of the gallbladder [1-3]. Today, up to $90 \%$ of all cholecystectomies are completed laparoscopically. The laparoscopic technique is associated with a faster recovery, a shorter length of stay and less complications such as pneumonia, pulmonary embolism, thrombosis and incisional hernias.

While the advantages of laparoscopy are well studied, controversies remain regarding the timing of the cholecystectomy. Early and same admission cholecystectomy for acute cholecystitis seems to be preferred due to lower morbidity rates, lower conversion rates, lower length of stay and lower hospital costs, even in cases with mild biliary pancreatitis [4-13]. An early operation can reduce the risk of recurrence or progression of the disease.

However, whether cholecystectomies should be performed during nighttime in patients with acute indications remains a controversial issue. $\mathrm{X}$. Wu et al. compared nighttime vs. daytime cholecystectomies for acute cholecystitis [14]. They analyzed 1140 patient and showed an increased conversion rate to open surgery for nighttime cases, however, with no influence on the length of stay or complication rates. They concluded that cholecystectomies should be performed during daytime. This conclusion, however, is not universally accepted-S. Siada et al. in contrast showed that there is no higher risk of complications for laparoscopic cholecystectomies performed during nighttime hours [15].

The aim of this study was to determine whether the timing of surgery has any impact on in-hospital complication rates or mortality in cholecystectomy in a national cohort study.

\section{Material and methods}

The prospective database of the Swiss working group for quality assurance in surgery (Arbeitsgemeinschaft für Qualitätssicherung in der Chirurgie "AQC" [16]) was queried to identify patients with an acute disease of the gallbladder requiring an operation. In Switzerland, over 70 hospitals provide standardized data of in-hospital surgical patients to the AQC. The AQC-database contains currently more than 1.5 million cases. To enter data for the AQCdatabase two forms must be filled in online with a) information on the inpatient treatment and b) on the operation(s). The recorded and for analysis available data are presented in Table 1 and 2. The World Health Organization's International Statistical Classification of Diseases and Related Health Problems (ICD-10) is used to code the diagnosis [17] and the Swiss operation classification "CHOP" for the procedures [18]. The study has been approved by the institutional review board-no special approval was needed due to de-identified data.

The inclusion criteria were operatively treated cholecystitis or another benign disease of the gallbladder, notably symptomatic cholecystolithiasis (ICD-diagnostic codes K80 to K83). The time of day a cholecystectomy was performed had to be recorded. (The start time of an operation is an optional field in the AQC-questionnaire.) The time span was 01/01/2010-12/31/2017. Exclusion criteria were missing data. A total of 11'459 patients were eventually included in our analysis.

The patients were stratified into two groups depending on the start of the surgical intervention: daytime (7AM until 6PM) and nighttime (7PM until 6AM).

Development of any complication during hospitalization and in-hospital mortality was the main outcomes.

To evaluate the influence of the daytime an operation was performed, we applied a case-control-matching. The goal was to match on confounding variables who account for pre-existing differences, to reduce selection bias and to improve internal validity. Using the case-control-matching feasibility in SPSS, we performed a one-to-one matching of our two different time groups (day- versus nighttime) sequentially on the basis of exact age, gender, ASA-Status (ASA I-V, however, for ASA IV and V we had no matches), admission type, insurance status, the presence of a comorbidity, the exact diagnosis, the training level of the surgeon and the type of surgery. A matched group of 274 pairs fulfilled the matching. (Table 3).

The data were downloaded via an online tool (AdjumedAnalyze, Adjumed Services AG, Zurich, Switzerland) and analyzed by using the Statistical Package for Social Sciences (SPSS, Version 24, IBM Corp., Armonk, New York, the USA).

The first part of the study was descriptive (continuous and categorical data). The second part was bivariate analysis. The normality of the data was assessed with the Kolmogorov-Smirnov test. The Chi-square, Mann-Whitney $\mathrm{U}$ and Fisher tests, where applicable, were used to do bivariate analysis. McNemar tests (for dichotomous categorical variables) and paired t-tests (for continuous variables) were used in bivariate analysis comparing our two matched groups (Table 4).

Factors associated with mortality were assessed in bivariate analysis only because of the low number of deaths. Risk factors for complications were evaluated in a stepwise backward likelihood logistic regression analysis. Significant $(p<0.05)$ or nearly significant factors $(p<0.1)$ in bivariate analysis were chosen as potential confounders. 
Table 1 Patient characteristics, day- vs. nighttime

\begin{tabular}{|c|c|c|c|c|c|c|c|c|}
\hline \multirow[t]{2}{*}{ Parameter } & & \multicolumn{2}{|c|}{$\begin{array}{l}\text { Total } \\
(n=11,459)\end{array}$} & \multicolumn{2}{|c|}{$\begin{array}{l}\text { Group daytime } \\
(n=10,495)\end{array}$} & \multicolumn{2}{|c|}{$\begin{array}{l}\text { Group nighttime } \\
(n=964)\end{array}$} & \multirow[t]{2}{*}{$p$ value } \\
\hline & & $n$ & $\%$ & $n$ & $\%$ & $n$ & $\%$ & \\
\hline Age (years) & mean $\pm \mathrm{SD}$ & $55 \pm 17$ & & $55 \pm 17$ & & $57 \pm 18$ & & 0.013 \\
\hline \multirow[t]{2}{*}{ Gender } & male & 4491 & 39 & 4074 & 39 & 417 & 43 & 0.007 \\
\hline & female & 6968 & 61 & 6421 & 61 & 547 & 57 & \\
\hline \multirow[t]{5}{*}{ ASA } & I (healthy person) & 3564 & 31 & 3311 & 32 & 253 & 26 & $<0.001$ \\
\hline & II (mild systemic disease) & 6496 & 57 & 5938 & 57 & 558 & 58 & \\
\hline & III (severe systemic disease) & 1351 & 12 & 1206 & 11 & 145 & 15 & \\
\hline & $\begin{array}{l}\text { IV (severe systemic disease that is a constant } \\
\text { threat to life) }\end{array}$ & 46 & 0.40 & 39 & 0.37 & 7 & 0.73 & \\
\hline & $\begin{array}{l}\mathrm{V} \text { (moribund person who is not expected to } \\
\text { survive without the operation) }\end{array}$ & 2 & 0.017 & 1 & 0.0095 & 1 & 0.10 & \\
\hline \multirow[t]{2}{*}{ Admission type } & emergency & 4382 & 38 & 3564 & 34 & 818 & 85 & $<0.001$ \\
\hline & registered, planned & 7077 & 62 & 6931 & 66 & 146 & 15 & \\
\hline \multirow[t]{2}{*}{ Insurance } & statutory & 9114 & 80 & 8301 & 79 & 813 & 84 & $<0.001$ \\
\hline & private & 2345 & 21 & 2194 & 21 & 151 & 16 & \\
\hline Length of stay (days) & mean $\pm \mathrm{SD}$ & $4.0 \pm 4.5$ & & $3.9 \pm 4.2$ & & $5.3 \pm 6.0$ & & $<0.001$ \\
\hline $\begin{array}{l}\text { Length of stay } \\
\text { preoperative (days) }\end{array}$ & mean $\pm \mathrm{SD}$ & $1.0 \pm 2.1$ & & $1.0 \pm 2.1$ & & $1.0 \pm 2.0$ & & n.s \\
\hline $\begin{array}{l}\text { Length of stay } \\
\text { postoperative } \\
\text { (days) }\end{array}$ & mean $\pm \mathrm{SD}$ & $3.0 \pm 3.6$ & & $2.9 \pm 3.4$ & & $4.3 \pm 5.1$ & & $<0.001$ \\
\hline Duration ICU (hours) & mean $\pm \mathrm{SD}$ & $1.3 \pm 16$ & & $1.2 \pm 17$ & & $2.5 \pm 14$ & & $<0.001$ \\
\hline Comorbidity & yes & 3161 & 28 & 2837 & 27 & 324 & 34 & $<0.001$ \\
\hline Intubation & yes & 808 & 7.1 & 758 & 7.2 & 50 & 5.2 & 0.018 \\
\hline \multirow[t]{6}{*}{ Discharge } & deceased & 64 & 0.56 & 59 & 0.56 & 5 & 0.52 & $<0.001$ \\
\hline & at home & 11,062 & 97 & 10,158 & 97 & 904 & 94 & \\
\hline & nursing home & 74 & 0.65 & 60 & 0.57 & 14 & 1.5 & \\
\hline & old people's home & 51 & 0.45 & 44 & 0.42 & 7 & 0.73 & \\
\hline & rehabilitation clinic & 58 & 0.51 & 43 & 0.41 & 15 & 1.6 & \\
\hline & other & 150 & 1.3 & 131 & 1.2 & 19 & 2.0 & \\
\hline \multirow[t]{10}{*}{ Diagnosis } & $\begin{array}{l}\text { K80 Calculus of gallbladder with acute } \\
\text { cholecystitis }\end{array}$ & 2857 & 25 & 2382 & 23 & 475 & 49 & $<0.001$ \\
\hline & $\begin{array}{l}\text { K80.1 Calculus of gallbladder with other } \\
\text { cholecystitis }\end{array}$ & 3826 & 33 & 3607 & 34 & 219 & 23 & \\
\hline & $\begin{array}{l}\text { K80.2 Calculus of gallbladder without } \\
\text { cholecystitis }\end{array}$ & 2768 & 24 & 2706 & 26 & 62 & 6.4 & \\
\hline & K80.3 Calculus of bile duct with cholangitis & 45 & 0.39 & 43 & 0.41 & 2 & 0.21 & \\
\hline & K80.4 Calculus of bile duct with cholecystitis & 185 & 1.6 & 177 & 1.7 & 8 & 0.83 & \\
\hline & $\begin{array}{l}\text { K80.5 Calculus of bile duct without cholangitis } \\
\text { or cholecystitis }\end{array}$ & 181 & 1.6 & 173 & 1.6 & 8 & 0.83 & \\
\hline & K80.8 Other cholelithiasis & 148 & 1.3 & 147 & 1.4 & 1 & 0.10 & \\
\hline & K81 Cholecystitis & 1304 & 11 & 1126 & 11 & 178 & 18 & \\
\hline & K82 Other diseases of gallbladder & 121 & 1.1 & 110 & 1.0 & 11 & 1.1 & \\
\hline & K83 Other diseases of biliary tract & 24 & 0.21 & 24 & 0.23 & 0 & 0 & \\
\hline
\end{tabular}

SD: standard deviation; ASA, American Society of Anesthesiologists classification system; n.s., not significant 
Table 2 Procedure characteristics, day- vs. nighttime

\begin{tabular}{|c|c|c|c|c|c|c|c|c|}
\hline \multirow[t]{2}{*}{ Parameter } & & \multicolumn{2}{|c|}{$\begin{array}{l}\text { Total } \\
(n=11,459)\end{array}$} & \multicolumn{2}{|c|}{$\begin{array}{l}\text { Group } \\
\text { daytime } \\
(n=10,495)\end{array}$} & \multicolumn{2}{|c|}{$\begin{array}{l}\text { Group } \\
\text { nighttime } \\
(n=964)\end{array}$} & \multirow[t]{2}{*}{$p$ value } \\
\hline & & $n$ & $\%$ & $n$ & $\%$ & $n$ & $\%$ & \\
\hline \multirow[t]{3}{*}{ Surgeon class } & senior attending & 4171 & 36 & 3950 & 38 & 221 & 23 & $<0.001$ \\
\hline & junior attending & 4413 & 39 & 3914 & 37 & 499 & 52 & \\
\hline & resident & 2875 & 25 & 2631 & 25 & 244 & 25 & \\
\hline \multirow[t]{3}{*}{ Type of surgery } & laparoscopically & 9715 & 85 & 9100 & 87 & 615 & 64 & $<0.001$ \\
\hline & conversion & 1403 & 12 & 1112 & 11 & 291 & 30 & \\
\hline & open & 341 & 3.0 & 283 & 2.7 & 58 & 6.0 & \\
\hline Duration surgery (minutes) & mean $\pm \mathrm{SD}$ & $86 \pm 49$ & & $85 \pm 48$ & & $99 \pm 55$ & & $<0.001$ \\
\hline Complications & yes & 763 & 6.7 & 645 & 6.1 & 118 & 12 & $<0.001$ \\
\hline Teaching & yes & 2684 & 23 & 2466 & 23 & 218 & 23 & 0.021 \\
\hline \multirow[t]{3}{*}{ Thromboembolism prophylaxis } & thromboembolism prophylaxis & 10,480 & 91 & 9575 & 91 & 905 & 94 & 0.017 \\
\hline & no thromboembolism prophylaxis & 648 & 5.7 & 607 & 5.8 & 41 & 4.3 & \\
\hline & anticoagulation & 331 & 2.9 & 313 & 3.0 & 18 & 1.9 & \\
\hline \multirow[t]{4}{*}{ Antibiotics } & no antibiotics & 1089 & 9.5 & 1041 & 9.9 & 48 & 5.0 & $<0.001$ \\
\hline & prophylactic antibiotics (before start of surgery) & 8376 & 73 & 7773 & 74 & 603 & 63 & \\
\hline & prophylactic antibiotics (after start of surgery) & 150 & 1.3 & 133 & 1.3 & 17 & 1.8 & \\
\hline & antibiotic therapy & 1844 & 16 & 1548 & 15 & 296 & 31 & \\
\hline
\end{tabular}

$S D$, standard deviation

A post hoc power analysis for complications determined that the total sample size of 548 patients provided $81 \%$ power.

\section{Results}

\section{The study population}

A total of 11'459 patients were examined in this study. The mean age was $55 \pm 17$ years. Sixty-one percent of the patients were female. Thirty-eight percent of the patients were admitted as emergencies. Fifty-seven percent of the examined patients had an ASA score of II (mild systemic disease). Twenty-eight percent of all patients suffered from at least one comorbidity. The most frequent diagnosis was K80.1 (calculus of the gallbladder with cholecystitis and with or without bile duct obstruction). Most operations were performed by junior attendings (39\% of all cases), followed by senior attendings $(36 \%)$. Eighty-five percent of the cholecystectomies were performed laparoscopically.

Complications arised in 6.7 percent of all patients. The most common complications were urinary retention, pneumonia, pancreatitis, cardiac arrhythmia, respiratory failure, sepsis and urinary tract infection. The most common intraoperative complications reported were lesion to the liver or liver bed, a gastrointestinal lesion and a lesion to the bile duct. The most common postoperative complications reported were wound healing disorder, post-bleeding anemia and bile fistula. The complication rates were similar between the two groups. (Supplementary Table 1).

Sixty-four patients $(0.56 \%)$ died during the hospitalization. The average length of stay was $4.0 \pm 4.5$ days. (Tables 1 and 2).

\section{Timing of surgery and outcome}

Only $8.4 \%$ of the procedures were performed during nighttime. The patients in the nighttime group had significantly more comorbidities, a slightly higher ASA-score, were more than twice as often assigned as emergency and were more often covered by statutory insurance plans than the patients operated on during daytime. (Table 1) Junior attendings and residents carried out $77 \%$ of all operations during nighttime. Duration of surgery was significantly longer in the nighttime group compared to the daytime group and lasted on average 14 min longer. (Table 2).

We found twice as many complications in the nighttime group (12\%) compared to the daytime group $(6.1 \%)$, which was significant. In-hospital mortality was $0.56 \%(n=59)$ during daytime and $0.52 \%(n=5)$ during nighttime. 
Table 3 Characteristics of matched daytime with nighttime cases

\begin{tabular}{|c|c|c|c|c|c|c|}
\hline \multirow[t]{2}{*}{ Parameter } & & \multicolumn{2}{|c|}{ Group daytime $(n=274)$} & \multicolumn{2}{|c|}{ Group nighttime $(n=274)$} & \multirow[t]{2}{*}{$p$ value } \\
\hline & & $n$ & $\%$ & $n$ & $\%$ & \\
\hline Age (years) & mean $\pm \mathrm{SD}$ & $55 \pm 16$ & & $55 \pm 16$ & & 1.0 \\
\hline \multirow[t]{2}{*}{ Gender } & male & 110 & 40 & 110 & 40 & 1.0 \\
\hline & female & 164 & 60 & 164 & 60 & \\
\hline \multirow[t]{3}{*}{ ASA } & I (healthy person) & 52 & 19 & 52 & 19 & 1.0 \\
\hline & II (mild systemic disease) & 198 & 72 & 198 & 72 & \\
\hline & III (severe systemic disease) & 24 & 8.8 & 24 & 8.8 & \\
\hline \multirow[t]{2}{*}{ Admission type } & emergency & 215 & 78 & 215 & 78 & 1.0 \\
\hline & registered, planned & 59 & 22 & 59 & 22 & \\
\hline \multirow[t]{2}{*}{ Insurance } & statutory & 251 & 92 & 251 & 92 & 1.0 \\
\hline & private & 23 & 8.4 & 23 & 8.4 & \\
\hline Comorbidity & yes & 65 & 24 & 65 & 24 & 1.0 \\
\hline \multirow[t]{4}{*}{ Diagnosis } & K80 Calculus of gallbladder with acute cholecystitis & 160 & 58 & 160 & 58 & 1.0 \\
\hline & K80.1 Calculus of gallbladder with other cholecystitis & 63 & 23 & 63 & 23 & \\
\hline & K80.2 Calculus of gallbladder without cholecystitis & 14 & 5.1 & 14 & 5.1 & \\
\hline & K81 Cholecystitis & 37 & 14 & 37 & 14 & \\
\hline \multirow[t]{3}{*}{ Surgeon class } & senior consultant, attending surgeon & 53 & 19 & 53 & 19 & 1.0 \\
\hline & junior consultant & 160 & 58 & 160 & 58 & \\
\hline & resident & 61 & 22 & 61 & 22 & \\
\hline \multirow[t]{2}{*}{ Type of surgery } & laparoscopically & 251 & 92 & 251 & 92 & 1.0 \\
\hline & conversion & 23 & 8.4 & 23 & 8.4 & \\
\hline
\end{tabular}

$S D$, standard deviation; $A S A$, American Society of Anesthesiologists classification system

Table 4 Outcome details of matched daytime with nighttime cases

\begin{tabular}{|c|c|c|c|c|c|c|}
\hline \multirow[t]{2}{*}{ Parameter } & & \multicolumn{2}{|c|}{ Group daytime $(n=274)$} & \multicolumn{2}{|c|}{ Group nighttime $(n=274)$} & \multirow[t]{2}{*}{$p$ value } \\
\hline & & $n$ & $\%$ & $n$ & $\%$ & \\
\hline Length of stay preoperative (days) & mean $\pm \mathrm{SD}$ & $1.4 \pm 1.9$ & & $0.69 \pm 1.2$ & & $<0.001$ \\
\hline Length of stay postoperative (days) & mean $\pm \mathrm{SD}$ & $3.0 \pm 2.1$ & & $3.9 \pm 4.0$ & & $<0.001$ \\
\hline Duration ICU (hours) & mean $\pm \mathrm{SD}$ & $1.0 \pm 7.2$ & & $2.6 \pm 15$ & & 0.128 \\
\hline Intubation & yes & 26 & 9.5 & 16 & 5.8 & 0.108 \\
\hline \multirow[t]{6}{*}{ Discharge } & deceased & 2 & 0.73 & 2 & 0.73 & 0.906 \\
\hline & at home & 261 & 95 & 260 & 95 & \\
\hline & nursing home & 2 & 0.73 & 3 & 1.1 & \\
\hline & old people's home & 3 & 1.1 & 2 & 0.73 & \\
\hline & rehabilitation clinic & 1 & 0.36 & 3 & 1.1 & \\
\hline & other & 5 & 1.8 & 4 & 1.5 & \\
\hline Duration surgery (minutes) & mean $\pm \mathrm{SD}$ & $97 \pm 49$ & & $92 \pm 42$ & & 0.164 \\
\hline Complications & yes & 23 & 8.4 & 27 & 9.9 & 0.527 \\
\hline Teaching & yes & 68 & 25 & 50 & 18 & 0.011 \\
\hline
\end{tabular}

$S D$, standard deviation 


\section{Matched-pair analysis}

The matching produced two groups with no significant differences in length of stay, time in the ICU, the need for intubation and duration of surgery. In our matched group, we found more teaching interventions in the daytime group than in the nighttime group.

The time of surgery (day- vs. nighttime) had no influence on the primary outcome: The complication rates were similar in our matched-pair analysis. In addition, the overall mortality rate in our matched-pairs analysis was $0.73 \%(0.73 \%$ in the daytime group and $0.73 \%$ in the nighttime group, n.s.). (Table 4).

\section{Bivariate and multivariate analysis}

Mortality was associated with higher age, higher ASA scores, longer ICU and hospital stays. Patients who died suffered more complications, underwent rather open than laparoscopic surgery and received more often antibiotic therapy (vs. prophylactic only) than patients who survived.

A higher age, a higher ASA-score, open surgery and conversion vs. laparoscopic operation, longer duration of the cholecystectomy, operation at nighttime vs. daytime, antibiotic therapy vs. no antibiotics and a private insurance status vs. statutory, were significant predictors of general and postoperative complications in multivariate analysis $(R$ square $=0.22)($ Table 5 and 6$)$.

\section{Discussion}

Most cholecystectomies are completed in a planned and elective setting during daytime. Obviously, some patients were unable to receive their elective cholecystectomy during the elective daytime schedule, and their operation was then performed by the on-call staff during nighttime so this patient would not have to be discharged and rescheduled for a later date. Under certain circumstances (symptomatic cholelithiasis or acute/gangrenous cholecystitis), it is necessary to perform the surgery also off-hours, in our study defined as the time between 7 PM until 6 AM to reduce the risk of recurrent complications. The aim of this study was to determine whether the timing of surgery has any impact on in-hospital outcome.

In summary, our data showed equal mortality but a higher morbidity in patients operated at night versus patients operated during daytime. However, patients who had undergone surgery in the off-hours were significantly older, had a higher ASA score, had more comorbidities and were more frequently operated on by junior attendings. And these patients had twice as many complications. Yet, a matched-pair analysis controlling for several risk factors such as patient age, gender, ASA class, severity of the disease and type of surgery found that outcomes did indeed not differ between day- and nighttime cholecystectomies. Therefore, we conclude that patient-related factors play a role in the observed increase in postoperative morbidity, but not the time of surgery. Alternatively, factors not

Table 5 Predictors for complications in all patients

\begin{tabular}{lrrr}
\hline Parameter & Sig & OR & \multicolumn{2}{c}{$95 \%$ C.I.for EXP(B) } \\
\cline { 2 - 4 } & & Lower & Upper \\
\hline ASA IV (vs. ASA I) & & 5.427 & 2.190 \\
ASA III (vs. ASA I) & $<0.001$ & 1.381 & 2.555 \\
Open (vs. laparoscopically) & $<0.001$ & 1.878 & 1.138 \\
Antibiotic therapy (vs. no antibiotics) & 0.007 & 1.622 & 1.074 \\
Conversion (vs. laparoscopically) & 0.021 & 1.607 & 1.116 \\
Nighttime (vs. daytime) & 0.004 & 1.403 & 1.703 \\
Insurance status private (vs. statutory) & 0.024 & 1.346 & 1.039 \\
ASA II (vs. ASA I) & 0.011 & 1.338 & 1.070 \\
Anticoagulation (vs. thromboembolism prophylaxis) & 0.021 & 1.330 & 1.044 \\
Age (years) & 0.194 & 1.308 & 0.872 \\
Duration surgery (minutes) & $<0.001$ & 1.015 & 1.009 \\
Antibiotic prophylaxis (before start of surgery) (vs. no antibiotics) & $<0.001$ & 1.014 & 1.013 \\
Antibiotic prophylaxis (after start of surgery) (vs. no antibiotics) & 0.858 & 0.925 & 0.394 \\
No thromboembolism prophylaxis (vs. thromboembolism prophylaxis) & $<0.001$ & 1.693 \\
\hline
\end{tabular}

Added in the analyze: age, duration of surgery, gender, ASA score (without ASA V), admission type, insurance status, comorbidity, diagnosis, surgeon class, type of surgery, teaching, thromboembolism prophylaxis, antibiotic therapy and day- or nighttime

$O R$, Odds ratio 
Table 6 Factors associated with mortality (bivariate analysis) in all patients

\begin{tabular}{|c|c|c|c|c|c|c|}
\hline \multirow[t]{2}{*}{ Parameter } & & \multicolumn{2}{|c|}{$\begin{array}{l}\text { Survivors } \\
(\mathrm{n}=11,395)\end{array}$} & \multicolumn{2}{|c|}{$\begin{array}{l}\text { Non-survivors } \\
(\mathrm{n}=64)\end{array}$} & \multirow[t]{2}{*}{$p$ value } \\
\hline & & $n$ & $\%$ & $n$ & $\%$ & \\
\hline Age (years) & mean $\pm \mathrm{SD}$ & $55 \pm 17$ & & $63 \pm 19$ & & $<0.001$ \\
\hline \multirow[t]{5}{*}{ ASA } & I (healthy person) & 3542 & 31 & 22 & 34 & $<0.001$ \\
\hline & II (mild systemic disease) & 6472 & 57 & 24 & 38 & \\
\hline & III (severe systemic disease) & 1338 & 12 & 13 & 20 & \\
\hline & IV (severe systemic disease that is a constant threat to life) & 41 & 0.36 & 5 & 7.8 & \\
\hline & $\begin{array}{l}\mathrm{V} \text { (moribund person who is not expected to survive without the } \\
\text { operation) }\end{array}$ & 2 & 0.018 & 0 & 0 & \\
\hline $\begin{array}{l}\text { Length of stay } \\
\text { (days) }\end{array}$ & mean $\pm \mathrm{SD}$ & $4.0 \pm 4.4$ & & $14 \pm 16$ & & $<0.001$ \\
\hline $\begin{array}{l}\text { Duration ICU } \\
\text { (hours) }\end{array}$ & mean \pm SD & $1.0 \pm 12$ & & $48 \pm 145$ & & $<0.001$ \\
\hline \multirow[t]{10}{*}{ Diagnosis } & K80 Calculus of gallbladder with acute cholecystitis & 2834 & 25 & 23 & 36 & 0.004 \\
\hline & K80.1 Calculus of gallbladder with other cholecystitis & 3813 & 33 & 13 & 20 & \\
\hline & K80.2 Calculus of gallbladder without cholecystitis & 2756 & 24 & 12 & 19 & \\
\hline & K80.3 Calculus of bile duct with cholangitis & 45 & 0.39 & 0 & 0 & \\
\hline & K80.4 Calculus of bile duct with cholecystitis & 180 & 1.6 & 5 & 7.8 & \\
\hline & K80.5 Calculus of bile duct without cholangitis or cholecystitis & 179 & 1.6 & 2 & 3.1 & \\
\hline & K80.8 Other cholelithiasis & 145 & 1.3 & 3 & 4.7 & \\
\hline & K81 Cholecystitis & 1299 & 11 & 5 & 7.8 & \\
\hline & K82 Other diseases of gallbladder & 121 & 1.1 & 0 & 0 & \\
\hline & K83 Other diseases of biliary tract & 23 & 0.20 & 1 & 1.6 & \\
\hline \multirow[t]{3}{*}{ Type of surgery } & laparoscopically & 9664 & 85 & 51 & 80 & 0.001 \\
\hline & conversion & 1397 & 12 & 6 & 9.4 & \\
\hline & open & 334 & 2.9 & 7 & 11 & \\
\hline Complications & yes & 739 & 6.5 & 24 & 38 & $<0.001$ \\
\hline \multirow[t]{4}{*}{ Antibiotics } & no antibiotics & 1082 & 9.5 & 7 & 11 & $<0.001$ \\
\hline & prophylactic antibiotics (before start of surgery) & 8348 & 73 & 28 & 44 & \\
\hline & prophylactic antibiotics (after start of surgery) & 149 & 1.3 & 1 & 1.6 & \\
\hline & antibiotic therapy & 1816 & 16 & 28 & 44 & \\
\hline
\end{tabular}

$S D$, standard deviation; $A S A$, American Society of Anesthesiologists classification system; n.s., not significant

accounted for in our administrative database, such as surgeon fatigue, may influence results of operations in patients of otherwise similar characteristics. This is in accordance with a study from the Netherlands. Geraedts et al. posed the question whether an off-hour laparoscopic cholecystectomy would really increase postoperative morbidity [19]. In her study, data from 1553 laparoscopic cholecystectomies between 2014 and 2016 were prospectively collected and analyzed. Similar to our study, the number of nighttime procedures was $9.3 \%$, compared to $8.4 \%$ in our case. The key message of her study was that a nighttime laparoscopic cholecystectomy is not an independent risk factor for increased postoperative morbidity, and therefore, the time of surgery is only a relative contraindication. However, Blohm et al. found somewhat higher frequencies of adverse events in patients operated on admission day and emphasized the importance of optimizing the patient before surgery [20]. Wu et al. showed that nighttime cholecystectomy is associated with an increased conversion to open surgery without decrease in length of stay or complications [14]. This is consistent with our findings. We found a considerably higher conversion rate in the nighttime group (30 vs. 11\%). The reasons seem multifactorial, the experience of the surgeon may contribute to this finding. However, we also think that this shows good surgical judgment and does not always represent a complication.

These statements are further strengthened by our multivariate and bivariate analysis.

Even in a subgroup analysis with a narrower definition of nighttime (11 PM to $6 \mathrm{AM}$ ), we found a similar cohort 
concerning age, sex and ASA with the same complication rate and from these 331 patients operated during nighttime none died during their stay in-hospital. (Supplementary Table 2 and 3 ).

The limitations of our large study include among others a selection bias in that we cannot deduce the individual decisions that have led to a nighttime cholecystectomy as opposed to a scheduled operation. Presumably, the reasons are in the context of the acute emergency and the vital threat.

\section{Conclusion}

We found twice as many complications in the nighttime group (12.2\%) compared to the daytime group (6.1\%), which was mainly based on patients being sicker and not on time of surgery. There is no significant effect of the time of day a cholecystectomy is performed regarding mortality. In contrast to common apprehension, however, nighttime cholecystectomies were not associated with higher mortality rates in our national sample. Urgent operations may therefore be performed at night without compromise in patient safety by surgeons trained and experienced in technically difficult cholecystectomies.

Funding Open Access funding provided by Universität Zürich.. This study was not funded.

\section{Declarations}

Conflict of interest All authors declare that they have no conflict of interest.

Ethical approval The study has been approved by the institutional review board-no special approval was needed due to de-identified data.

Open Access This article is licensed under a Creative Commons Attribution 4.0 International License, which permits use, sharing, adaptation, distribution and reproduction in any medium or format, as long as you give appropriate credit to the original author(s) and the source, provide a link to the Creative Commons licence, and indicate if changes were made. The images or other third party material in this article are included in the article's Creative Commons licence, unless indicated otherwise in a credit line to the material. If material is not included in the article's Creative Commons licence and your intended use is not permitted by statutory regulation or exceeds the permitted use, you will need to obtain permission directly from the copyright holder. To view a copy of this licence, visit http://creativecommons. org/licenses/by/4.0/.

\section{References}

1. Litwin DE, Cahan MA (2008) Laparoscopic cholecystectomy. SurgClin North Am 88(1295-1313):ix

2. Ibrahim M, Sarvepalli S, Morris-Stiff G et al (2018) Gallstones: Watch and wait, or intervene? Cleve Clin J Med 85:323-331

3. Lamberts MP (2018) Indications of cholecystectomy in gallstone disease. CurrOpinGastroenterol 34:97-102

4. Thangavelu A, Rosenbaum S, Thangavelu D (2018) Timing of Cholecystectomy in Acute Cholecystitis. J Emerg Med 54:892-897

5. Tan JK, Goh JC, Lim JW et al (2017) Same admission laparoscopic cholecystectomy for acute cholecystitis: is the "golden 72 hours" rule still relevant? HPB: the official journal of the International HepatoPancreato Biliary Association 19:47-51

6. Eubanks RD, Hassler KR, Huish G et al (2019) Review of Operative Treatment of Delayed Presentation of Acute Cholecystitis. Am Surg 85:98-102

7. Kohga A, Suzuki K, Okumura T et al (2019) Is postponed laparoscopic cholecystectomy justified for acute cholecystitis appearing early after onset? Asian j EndoscSurg 12:69-73

8. Yang DJ, Lu HM, Guo Q et al (2018) Timing of Laparoscopic Cholecystectomy After Mild Biliary Pancreatitis: A Systematic Review and Meta-Analysis. J LaparoendoscAdvSurg Tech A 28:379-388

9. van Baal MC, Besselink MG, Bakker OJ et al (2012) Timing of cholecystectomy after mild biliary pancreatitis: a systematic review. Ann Surg 255:860-866

10. Lyu Y, Cheng Y, Wang B et al (2018) Early versus delayed laparoscopic cholecystectomy for acute cholecystitis: an up-todate meta-analysis of randomized controlled trials. SurgEndosc 32:4728-4741

11. Lyu YX, Cheng YX, Jin HF et al (2018) Same-admission versus delayed cholecystectomy for mild acute biliary pancreatitis: a systematic review and meta-analysis. BMC Surg 18:111

12. Borreca D, Bona A, Bellomo MP et al (2016) Timing of cholecystectomy in acute biliary pancreatitis: is it still reasonable to wait? Minerva Chir 71:31-37

13. Friis C, Rothman JP, Burcharth J et al (2018) Optimal Timing for Laparoscopic Cholecystectomy After Endoscopic Retrograde Cholangiopancreatography: A Systematic Review. Scandinavian journal of surgery: SJS: official organ for the Finnish Surgical Society and the Scandinavian Surgical Society 107:99-106

14. Wu JX, Nguyen AT, de Virgilio C et al (2014) Can it wait until morning? A comparison of nighttime versus daytime cholecystectomy for acute cholecystitis. Am J Surg 208:911-918

15. Siada SS, Schaetzel SS, Chen AK et al (2017) Day versus night laparoscopic cholecystectomy for acute cholecystitis: A comparison of outcomes and cost. Am J Surg 214:1024-1027

16. surgery Swgfqai Swiss working group for quality assurance in surgery - Startpage, 2018; Start-Page AQC.

17. Organization WH WHO ICD-10 codes, WHO, 2018.

18. Statistik Bf Schweizerische Operationsklassifikation (CHOP)Version 2018, Bundesamt für Statistik, 2018.

19. Geraedts ACM, Sosef MN, Greve JWM et al (2018) Is Nighttime Really Not the Right Time for a Laparoscopic Cholecystectomy? Can j gastroenterolhepatol 2018:6076948

20. Blohm M, Österberg J, Sandblom G et al (2017) The Sooner, the Better? The Importance of Optimal Timing of Cholecystectomy in Acute Cholecystitis: Data from the National Swedish Registry for Gallstone Surgery, GallRiks. J GastrointestSurg 21:33-40

Publisher's Note Springer Nature remains neutral with regard to jurisdictional claims in published maps and institutional affiliations. 